\title{
Occipital Neuralgia after Occipital Cervical Fusion to Treat an Unstable Jefferson Fracture
}

\author{
Seong Ju Kong', Jin Hoon Park ${ }^{1}$, Sung Woo Roh ${ }^{2}$ \\ IDepartment of Neurological Surgery, Gangneung Asan Hospital, University of Ulsan College of Medicine, \\ Gangneung, Republic of Korea \\ ${ }^{2}$ Department of Neurological Surgery, Asan Medical Center, College of Medicine, University of Ulsan, \\ Seoul, Republic of Korea
}

In this report we describe a patient with an unstable Jefferson fracture who was treated by occipitocervical fusion and later reported sustained postoperative occipital neuralgia. A 70-year-old male was admitted to our center with a Jefferson fracture induced by a car accident. Preoperative lateral X-ray revealed an atlanto-dens interval of $4.8 \mathrm{~mm}$ and a C1 canal anteriorposterior diameter of $19.94 \mathrm{~mm}$. We performed fusion surgery from the occiput to C5 without decompression of C1. The patient reported sustained continuous pain throughout the following year despite strong analgesics. The pain dermatome was located mainly in the great occipital nerve territory and posterior neck. Magnetic resonance images revealed no evidence of cord compression, however a C1 lamina compressed dural sac and C2 root compression could not be excluded. We performed bilateral C2 root decompression via a C1 laminectomy. After decompression, bilateral C2 root redundancy was identified by palpation. After decompression surgery, pain was reduced. This case indicates that occipital neuralgia, suggesting the need for diagnostic block, should be considered in the differential diagnosis of patients with sustained occipital headache after occipitocervical fusion surgery.

Key Words: Spinal Fracture $\cdot$ Cervical Atlas $\cdot$ Nerve root compression

\section{INTRODUCTION}

The pathogenesis of occipital neuralgia is unclear, with diagnosis dependent on diagnostic block. Although there have been several studies of the cause of occipital neuralgia, none has reported occipital neuralgia caused by direct compression of the $\mathrm{C} 2$ nerve root after treatment of a Jefferson fracture ${ }^{4,9)}$. Here, we describe a patient with an unstable Jefferson fracture who was treated by occipitocervical fusion and later reported sustained postoperative occipital neuralgia.

\footnotetext{
- Received: October 4, 2012 - Revised: November 12, 2012

- Accepted: December 14, 2012

Corresponding Author: Sung Woo Roh, MD, PhD

Department of Neurological Surgery, Asan Medical Center, University of Ulsan College of Medicine, 388-1 Pungnap-2dong, Songpa-gu,

Seoul 138-736, Republic of Korea

Tel: +82-2-3010-3550, Fax: +82-2-476-6738

E-mail: swroh@amc.seoul.kr

The authors do not have any financial interest in this manuscript. There is no ethical conflict related to this manuscript.
}

\section{CASE REPORT}

A 70-year-old male was admitted to our center with a Jefferson fracture caused by a car accident. The patient reported neck pain with an intensity of 7-8 on a visual analog scale ranging from $0-10$, without any neurological deficit other than combined injury. A preoperative open mouth view showed a $7.26 \mathrm{~mm}$ lateral displacement of the $\mathrm{C} 1$ to the $\mathrm{C} 2$ lateral mass. Preoperative lateral X-ray also revealed an atlanto-dens interval of $4.39 \mathrm{~mm}$ and a $\mathrm{C} 1$ canal anterior-posterior diameter of $20.20 \mathrm{~mm}$. Preoperative magnetic resonance imaging (MRI) and computed tomography showed fractures of the bilateral anterior arch and the left side posterior arch of $\mathrm{C} 1$, and injury to the transverse ligament. Although there was no cord compression or abnormal cord signal change, mild dural sac compression of the left lateral side was observed (Fig. 1).

We decided to perform fusion surgery from the occiput to C5 without decompression of C1. The C1 lamina was used as a fusion bed with an iliac bone block from the occiput and $\mathrm{C} 2$, and further bone fusion from the occiput to $\mathrm{C} 5$ was per 


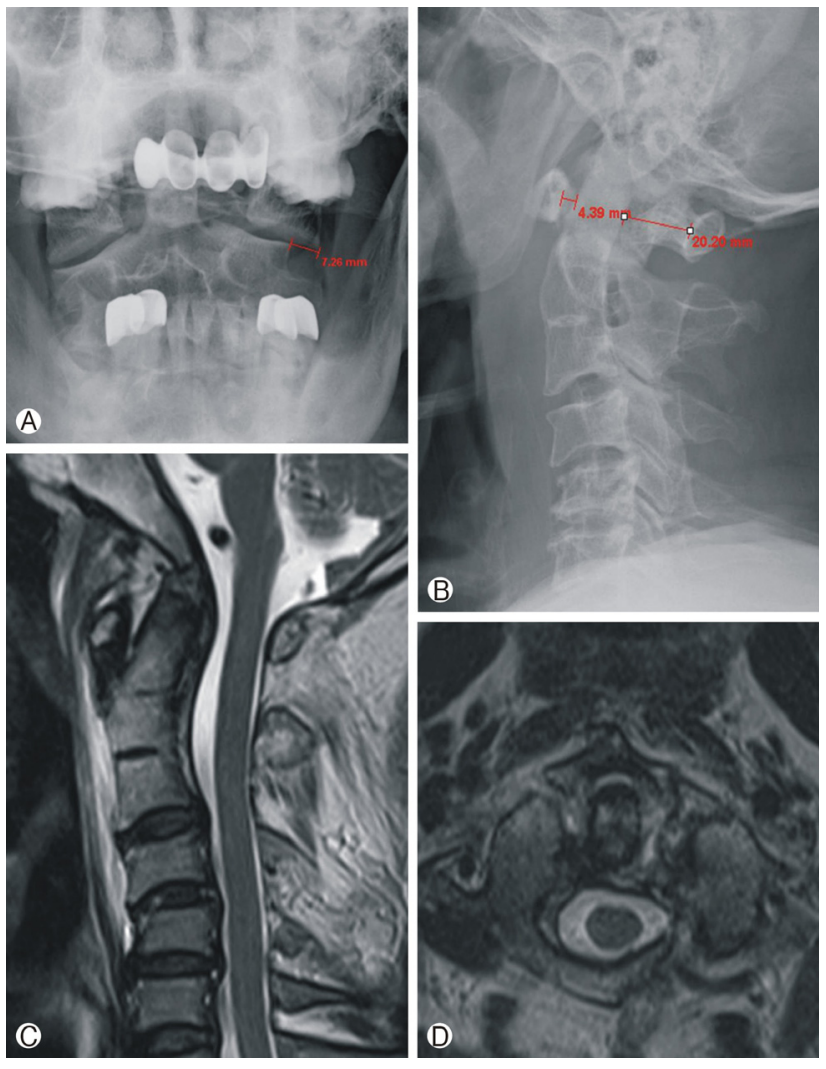

Fig. 1. (A) Preoperative open mouth view, showing a $7.26 \mathrm{~mm}$ displacement of the left $\mathrm{C} 1$ lateral mass to the $\mathrm{C} 2$ lateral mass. (B) Preoperative lateral X-ray showing a $4.39 \mathrm{~mm}$ atlanto-dens interval and a $\mathrm{Cl}$ canal diameter of $20.20 \mathrm{~mm}$. (C) Preoperative T2-weighted midline magnetic resonance sagittal image showing an absence of cord compression. (D) Preoperative T2-weighted magnetic resonance axial image at C1-C2 level revealing a Jefferson fracture, injury to the transverse ligament, and dural compression of the left side fractured lamina.

formed using iliac bone chips. Postoperative lateral X-rays showed an atlanto-dens interval of $3.12 \mathrm{~mm}$ and a $\mathrm{C} 1$ canal anterior-posterior diameter of $15.13 \mathrm{~mm}$ (Fig. 2). There were no complications during or after surgery. The patient had normal neurological status, but reported neck pain and occipital headache, which we initially believed was part of the normal postoperative course; however, the patient reported sustained continuous pain for 1 year, despite strong analgesics. The pain dermatome was located mainly in the great occipital nerve territory and posterior neck (Fig. 3). Although MRI revealed no evidence of cord compression, a C1 lamina compressed dural sac and C2 root compression could not be excluded (Fig. 4). From the pain dermatome and C1 lamina-induced dural compression we suspected C2 compression. A diagnostic bilateral C2 root block resulted in mild pain improvement; therefore, we decided to decompress the canal and bilateral

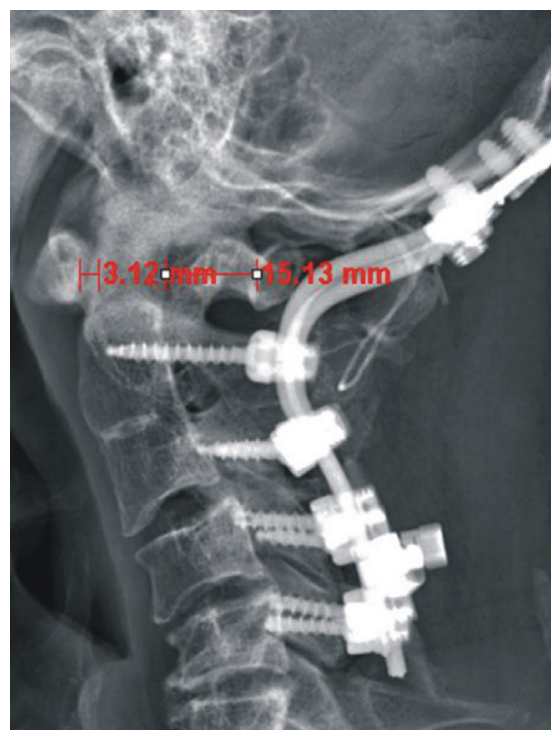

Fig. 2. Immediate postoperative lateral X-ray showing a 3.12 $\mathrm{mm}$ atlanto-dens interval and a $\mathrm{Cl}$ canal diameter of $15.13 \mathrm{~mm}$. lliac bone block with wiring between the occiput and C2 is also visible.
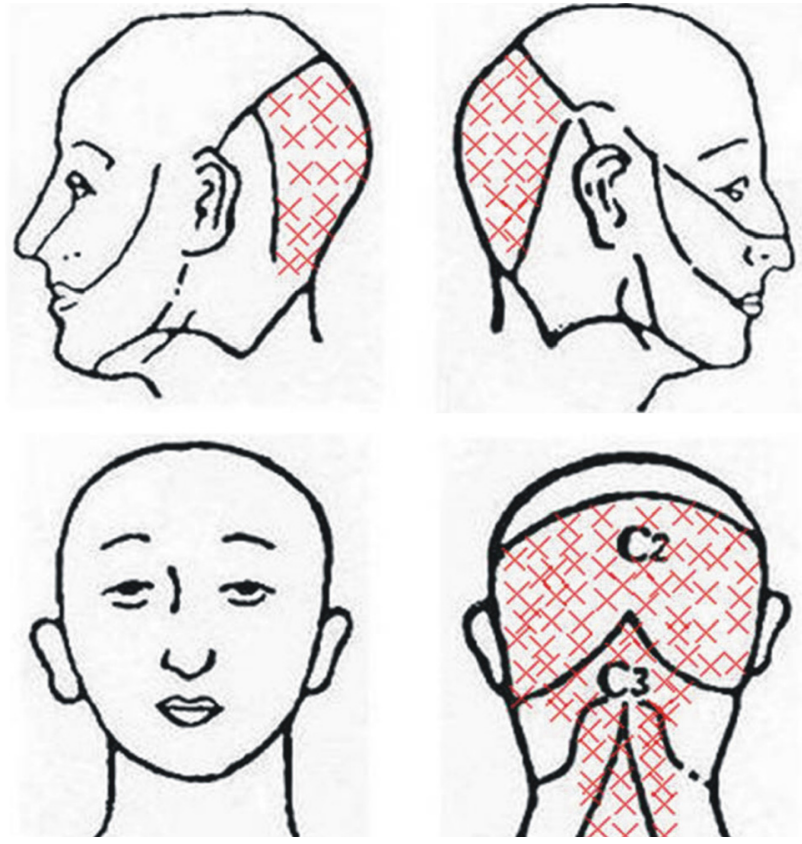

Fig. 3. Postoperative pain was located mainly in the C2 dermatome.

C2 roots surgically. During the operation, we found that the previous implantation of bone chips had resulted in firm bone stability and rigid bone fusion; however, we also observed a bone block resorption from the occiput to the $\mathrm{C} 2$ as well as replacement by thick fibrous tissue. Removal of the latter showed that the $\mathrm{C} 1$ posterior arch had severely compressed 


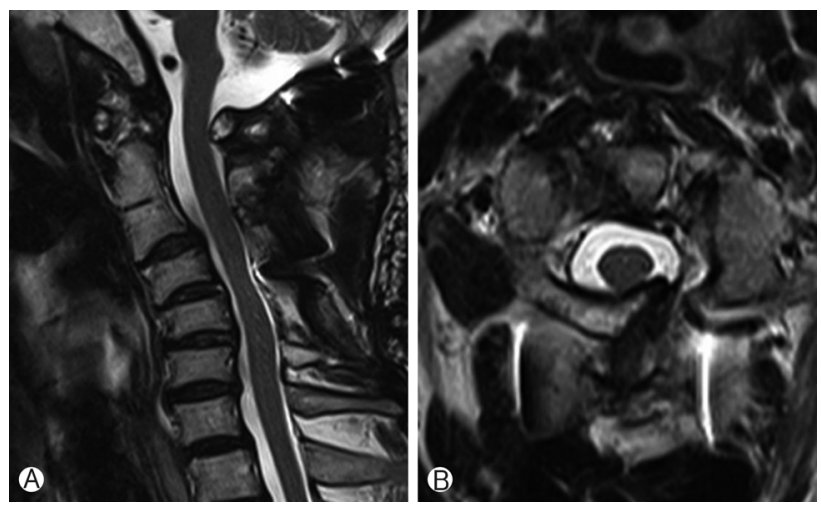

Fig. 4. (A) One year post-operative T2-weighted midline magnetic resonance sagittal image showing contact between the $\mathrm{Cl}$ posterior arch and cord, indicating narrowing of the canal compared to the preoperative magnetic resonance image. (B) One year post-operative T2-weighted magnetic resonance axial image at the $\mathrm{Cl}-\mathrm{C} 2$ level showing $\mathrm{Cl}$ laminar compression of the dura compared to the preoperative magnetic resonance image.
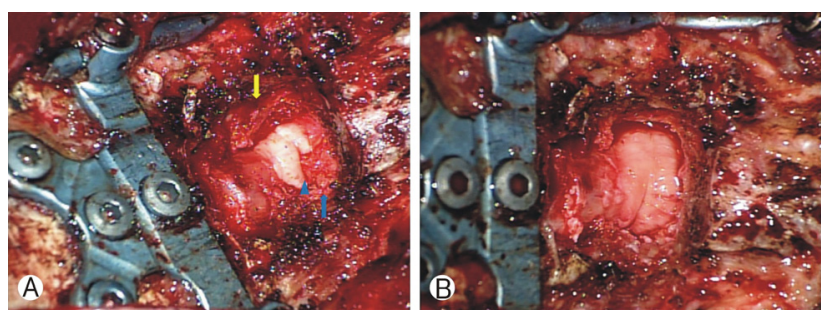

Fig. 5. (A) The $\mathrm{Cl}$ lamina (blue arrow) was partially removed. Dural compression of the $\mathrm{Cl}$ lamina was observed (blue arrowhead). The remaining $\mathrm{Cl}$ lamina also compressed the lateral side of the dura (yellow arrow). (B) Dura release after decompression. Bilateral root redundancy was identified by palpation.

the dural sac. We therefore performed bilateral $\mathrm{C} 2$ nerve root decompression followed by central canal decompression. After identifying bilateral C2 root redundancy by palpation, we completed the surgery (Fig. 5). One month later, the patient reported improvement of the occipital and neck pain (intensity of 1-2 on a visual analog scale).

\section{DISCUSSION}

Although occipitocervical fusion has been used to treat unstable Jefferson fractures, advances in surgical techniques have resulted in the preservation of normal cervical motion ${ }^{6,11)}$. We therefore thought that our patient could be treated successfully by C1-C2 fusion or bilateral C1 fixation and fusion. Our findings, however, suggest that uninstrumented C1 lamina may result in an iatrogenic dural sac and bilateral C2 nerve compression.
Occipital neuralgia has many causes including C1 lateral mass screw irritation and $\mathrm{C} 2$ nerveroot retraction during C1$\mathrm{C} 2$ fusion $^{1,2,4,5,7)}$. However, direct compression of the C2 nerve rootafter treatment of a Jefferson fracture has not previously been described. Occipital neuralgia in our patient may have been caused by direct dural compression or bilateral $\mathrm{C} 2$ root compression by the $\mathrm{C} 1$ posterior arch. The canal diameter decreased from $20.20 \mathrm{~mm}$ before surgery to $15.13 \mathrm{~mm}$ after the surgery, despite an improvement in the atlanto-dens interval. We attempted to compress the iliac bone block to the $\mathrm{C} 1$ posterior arch with a wire to achieve good fusion; however, this maneuver resulted in compression of the dura by the $\mathrm{C} 1$ posterior arch. Another possible cause of root compression was the rotation of the $\mathrm{C} 1$ posterior arch caused by the surgical position. If we had instrumented only $\mathrm{C} 1$ and $\mathrm{C} 2$, this might not have occurred because the cross link might have pulled each C1 lateral mass towards the center, resulting in a more posterior location of the $\mathrm{C} 1$ posterior arch. However, the surgical option we chose resulted in more anterior displacement of the $\mathrm{C} 1$ posterior arch caused by an iliac bone block. Iliac bone fusion mass resorption may be related to instability in the $\mathrm{C} 1$ posterior arch and an immobile structure without instrumentation.

Surgical indications for occipitocervical fusion include atlantooccipital dissociation, occipital condyle fractures, and rheumatoid arthritis ${ }^{3)}$. When $\mathrm{C} 1$ instrumentation is impossible, a postinstrumentation change in canal distance should be considered if the $\mathrm{C} 1$ posterior arch could be preserved.

The C2 nerve root is susceptible to injury or entrapment that can be treated by several surgical and diagnostic procedures $^{8,10)}$. Diagnostic block seems to be the most important tool for detecting the offending lesion.

In summary, this case showed pain in the typical dermatome of the $\mathrm{C} 2$ nerve root and we identified a possible cause as $\mathrm{C} 2$ nerve compression with diagnostic block. This case indicates that, after occipitocervical fusion, postoperative occipital neuralgia should be considered in possible differential diagnosis as a complication.

\section{CONCLUSION}

We have described a patient who, after occipitocervical fusion without $\mathrm{C} 1$ laminectomy, experienced occipital neuralgia associated with central and lateral compression of the $\mathrm{C} 1$ posterior arch. An intraoperative change in canal diameter may be a cause of such a complication should be considered. Occi- pital neuralgia, suggesting the need for diagnostic block, should be considered in the differential diagnosis of patients who complain of sustained occipital headache after this type of the surgery. 


\section{REFERENCES}

1. Bogduk N: The anatomical basis for cervicogenic headache. J Manipulative Physiol Ther 15:67-70, 1992

2. Conroy E, Laing A, Kenneally R, Poynton AR: C1 lateral mass screw-induced occipital neuralgia: a report of two cases. Eur Spine J 19(3):474-476, 2010

3. Finn MA, Bishop FS, Dailey AT: Surgical treatment of occipitocervical instability. Neurosurgery 63(5):961-968; discussion 968969, 2008

4. Haldeman S, Dagenais S: Cervicogenic headaches: a critical review. Spine J 1(1):31-46, 2001

5. Jansen J, Bardosi A, Hildebrandt J, Lucke A: Cervicogenic, hemicranial attacks associated with vascular irritation or compression of the cervical nerve root C2. Clinical manifestations and morphological findings. Pain 39(2):203-212, 1989

6. Li L, Teng H, Pan J, Qian L, Zeng C, Sun G, et al: Direct pos-

terior c1 lateral mass screws compression reduction and osteosynthesis in the treatment of unstable jefferson fractures. Spine (Phila Pa 1976) 36(15):E1046-1051, 2011

7. Park SY, Kang DH, hwang SH, Park IS, Jung JM, Han JW: Clinical experiences with posterior atlantoaxial fixation with a polyaxial screw and rod system. Korean J Spine 3:133-138, 2006

8. Poletti CE, Sweet WH: Entrapment of the $\mathrm{C} 2$ root and ganglion by the atlanto-epistrophic ligament: clinical syndrome and surgical anatomy. Neurosurgery 27(2):288-291, 1990

9. Pollmann W, Keidel M, Pfaffenrath V: Headache and the cervical spine: a critical review. Cephalalgia 17(8):801-816, 1997

10. Stechison MT, Mullin BB: Surgical treatment of greater occipital neuralgia: an appraisal of strategies. Acta Neurochir (Wien) 131(3-4):236-240, 1994

11. Tan J, Li L, Sun G, Qian L, Yang M, Zeng C, et al: C1 lateral mass-C2 pedicle screws and crosslink compression fixation for unstable atlas fracture. Spine (Phila Pa 1976) 34(23):2505-2509, 2009 